\title{
Use of balloon dilatation to treat supravalvar pulmonary stenosis developing after anatomical correction for complete transposition
}

\author{
Anita Saxena, Lance V Fong, Bruce C Ogilvie, Barry R Keeton
}

\begin{abstract}
Eight balloon dilatations were performed in five patients (aged from 10 to 37 months) in whom supravalvar pulmonary stenosis developed after anatomical correction for complete transposition. The ratio of the maximum diameter of the inflated balloon to the narrowest pulmonary arterial diameter varied from 1.6 to 3.3 . In three patients with an initial ratio of $\leqslant 2$ dilatation was repeated with a larger balloon. The right ventricular systolic pressure ranged from 0.70 to 1.25 of the simultaneously measured femoral arterial systolic pressure. The major stenosis was in the main pulmonary artery in four patients and at the pulmonary arterial bifurcation in one. After balloon angioplasty in the four patients there was no significant improvement in the ratio of right ventricular to femoral arterial systolic pressure or in the angiographic appearance. There was no change in the pressure ratio after angioplasty in the patient who had a major stenosis of the pulmonary arterial bifurcation and mild main pulmonary artery narrowing. There seemed to be a slight angiographic improvement in the bifurcation stenosis but at restudy two months later the angiographic improvement had disappeared.

Balloon angioplasty of supravalvar pulmonary stenosis developing after anatomical correction for complete transposition was not successful in eight procedures. This lack of success may be attributable to a small pulmonary annulus with consequent multiple levels of stenosis and distortion of the main pulmonary artery.
\end{abstract}

Over the past few years balloon dilatation procedures have been increasingly used to treat various congenital heart defects. When they are successful major cardiac operation can be avoided or delayed. Balloon dilatation is now an established treatment for certain defects such as pulmonary valve stenosis or recoarctation. Its value in other conditions such as native coarctation or pulmonary vein stenosis remains controversial. ${ }^{1}$ We performed balloon dilatation in five patients in whom supravalvar pulmonary stenosis developed after anatomical correction for complete transposition of the great arteries.
Patients and methods

Balloon dilatation of supravalvar pulmonary stenosis after the anatomical correction for complete transposition was attempted in eight patients. In three patients it could not be successfully undertaken because the stenotic segment could not be crossed with the balloon. Two of these patients had bilateral ileofemoral venous thrombosis, and successful balloon catheter manipulation could not be achieved from the internal jugular vein. The remaining five patients underwent balloon dilatation. In three of the five patients the dilatation was later repeated with a larger balloon; there were eight dilatation procedures in total.

The five patients were boys who were aged 10 to 37 months (median 15 months) at the time of balloon dilatation. Anatomical correction for complete transposition had been performed 7-17 days after birth. During operation autologous pericardium was used to augment the new pulmonary artery anastomosis in two patients. Preserved bovine pericardium was used in the other three patients. There were no other cardiac abnormalities except a small mid-muscular ventricular septal defect in one patient. This was closed at surgical correction.

Each patient had clinical, electrocardiographic, and echocardiographic findings typical of considerable supravalvar pulmonary stenosis. Cardiac catheterisation was performed under general anaesthesia. A decision to undertake balloon angioplasty was made if $(a)$ the right ventricular systolic pressure exceeded $66 \%$ of the femoral arterial systolic pressure and (b) angiography showed a considerably narrowed segment in the supravalvar region of the right ventricular outflow tract.

The internal diameters of the narrowest segment and the pulmonary annulus were measured from selected right ventricular angiographic images. These measurements were taken from cinevideo images and corrected for magnification with a $1 \mathrm{~cm}$ grid recorded in the approximate position of the patient's right ventricular outflow tract. A balloon diameter of 2-3 times the diameter of the narrowest segment and not exceeding 1.3 times the pulmonary annulus diameter was chosen. The stenotic segment was crossed initially with an end hole catheter and a J tip Teflon coated exchange guide wire positioned in a peripheral pulmonary artery. A balloon angioplasty catheter (Medi-tech, Mansfield 
Table 1 Data from cardiac catheterisation and angiocardiography

\begin{tabular}{|c|c|c|c|c|c|c|}
\hline Patients & $\begin{array}{l}\text { Age at } \\
\text { dilatation (mnth) }\end{array}$ & $\begin{array}{l}\text { Major } \\
\text { stenosis }\end{array}$ & $\begin{array}{l}P V \text { annulus } \\
\text { diameter ( } \mathrm{mm} \text { ) }\end{array}$ & $\begin{array}{l}\text { Narrowest } \\
\text { diameter ( } \mathrm{mm} \text { ) }\end{array}$ & $\begin{array}{l}\text { Balloon } \\
\text { diameter ( } \mathrm{mm} \text { ) }\end{array}$ & $\begin{array}{l}\text { Ratio of balloon to } \\
\text { narrowest diameter }\end{array}$ \\
\hline $\begin{array}{r}1 \mathrm{a} \\
\mathrm{b} \\
2 \mathrm{a} \\
\mathrm{b} \\
3 \\
4 \\
5 \mathrm{a} \\
\\
\mathrm{b}\end{array}$ & $\begin{array}{l}19 \\
22 \\
12 \\
15 \\
37 \\
10 \\
10 \\
12\end{array}$ & $\begin{array}{l}\text { MPA } \\
\text { MPA } \\
\text { MPA } \\
\text { MPA } \\
\text { MPA } \\
\text { MPA } \\
\text { LPA } \\
\text { RPA } \\
\text { LPA } \\
\text { RPA }\end{array}$ & $\begin{array}{r}9.5 \\
9.8 \\
9.0 \\
9.0 \\
11.5 \\
9.0 \\
11.0 \\
11.0\end{array}$ & $\begin{array}{l}5.0 \\
5.5 \\
4.0 \\
4.4 \\
7.0 \\
6.0 \\
3.0 \\
4.8 \\
3.0 \\
5.0\end{array}$ & $\begin{array}{r}8 \\
12 \\
7 \\
10 \\
13 \\
12 \\
6 \\
10\end{array}$ & $\begin{array}{l}1.6 \\
2.2 \\
1.7 \\
2.3 \\
1.8 \\
2.0 \\
2.0 \\
\\
3.3\end{array}$ \\
\hline
\end{tabular}

LPA, left pulmonary artery; MPA, main pulmonary artery; PV, pulmonary valve; RPA, right pulmonary artery.

Table 2 Results of balloon dilatation

\begin{tabular}{|c|c|c|c|c|c|c|}
\hline \multirow[b]{2}{*}{ Patient } & \multicolumn{3}{|c|}{ Before dilatation } & \multicolumn{3}{|c|}{ After dilatation } \\
\hline & $\begin{array}{l}R V \mid F A \\
\text { pressure ratio }\end{array}$ & $\begin{array}{l}P A \text { to } R V \\
\text { gradient }(m m \mathrm{Hg})\end{array}$ & $\begin{array}{l}\text { Narrowest } \\
\text { diameter ( } \mathrm{mm} \text { ) }\end{array}$ & $\begin{array}{l}R V / F A \\
\text { pressure ratio }\end{array}$ & $\begin{array}{l}P A \text { to } R V \\
\text { gradient }(m m \mathrm{Hg})\end{array}$ & $\begin{array}{l}\text { Narrowest } \\
\text { diameter }(\mathrm{mm})\end{array}$ \\
\hline $\begin{array}{r}1 a \\
b \\
2 a \\
b \\
3 \\
4 \\
5 a\end{array}$ & $\begin{array}{l}0.70 \\
0.85 \\
1.25 \\
0.90 \\
0.70 \\
0.70 \\
0.95\end{array}$ & $\begin{array}{l}50 \\
60 \\
80 \\
60 \\
55 \\
38 \\
70\end{array}$ & $\begin{array}{l}5 \cdot 0 \\
5 \cdot 5 \\
4 \cdot 0 \\
4 \cdot 4 \\
7 \cdot 0 \\
6.0 \\
3 \cdot 0 \text { (LPA) } \\
4.8 \text { (RPA) }\end{array}$ & $\begin{array}{l}0.80 \\
0.95 \\
1.15 \\
0.90 \\
0.70 \\
0.80 \\
0.90\end{array}$ & $\begin{array}{l}50 \\
60 \\
70 \\
55 \\
50 \\
40 \\
70\end{array}$ & $\begin{array}{l}5 \cdot 0 \\
5.5 \\
4.0 \\
4 \cdot 4 \\
7 \cdot 2 \\
6 \cdot 0 \\
3 \cdot 5 \text { (LPA) } \\
4.8 \text { (RPA) }\end{array}$ \\
\hline b & 0.90 & 65 & $\begin{array}{l}3.0 \text { (LPA) } \\
5.0 \text { (RPA) }\end{array}$ & $1 \cdot 10$ & 70 & $\begin{array}{l}3.0 \text { (LPA) } \\
5.2 \text { (RPA) }\end{array}$ \\
\hline
\end{tabular}

FA, femoral artery; LPA, left pulmonary artery; PA, pulmonary artery; RPA, right pulmonary artery; RV, right ventricle.

Figure 1 Anteroposterior and lateral views of a right ventriculogram showing supravalvar pulmonary stenosis with hypoplasia of the pulmonary trunk

(arrows) before ( $A$ ) and after ( $B$ ) balloon dilatation. 
Figure 2 Anteroposterior and lateral views of a right ventriculogram showing bifurcation stenosis, a particularly severe stenosis at the origin of the left pulmonary artery (small arrow), and mild supravalvar pulmonary stenosis (big arrow) before ( $A)$ and after $(B)$ balloon dilatation.
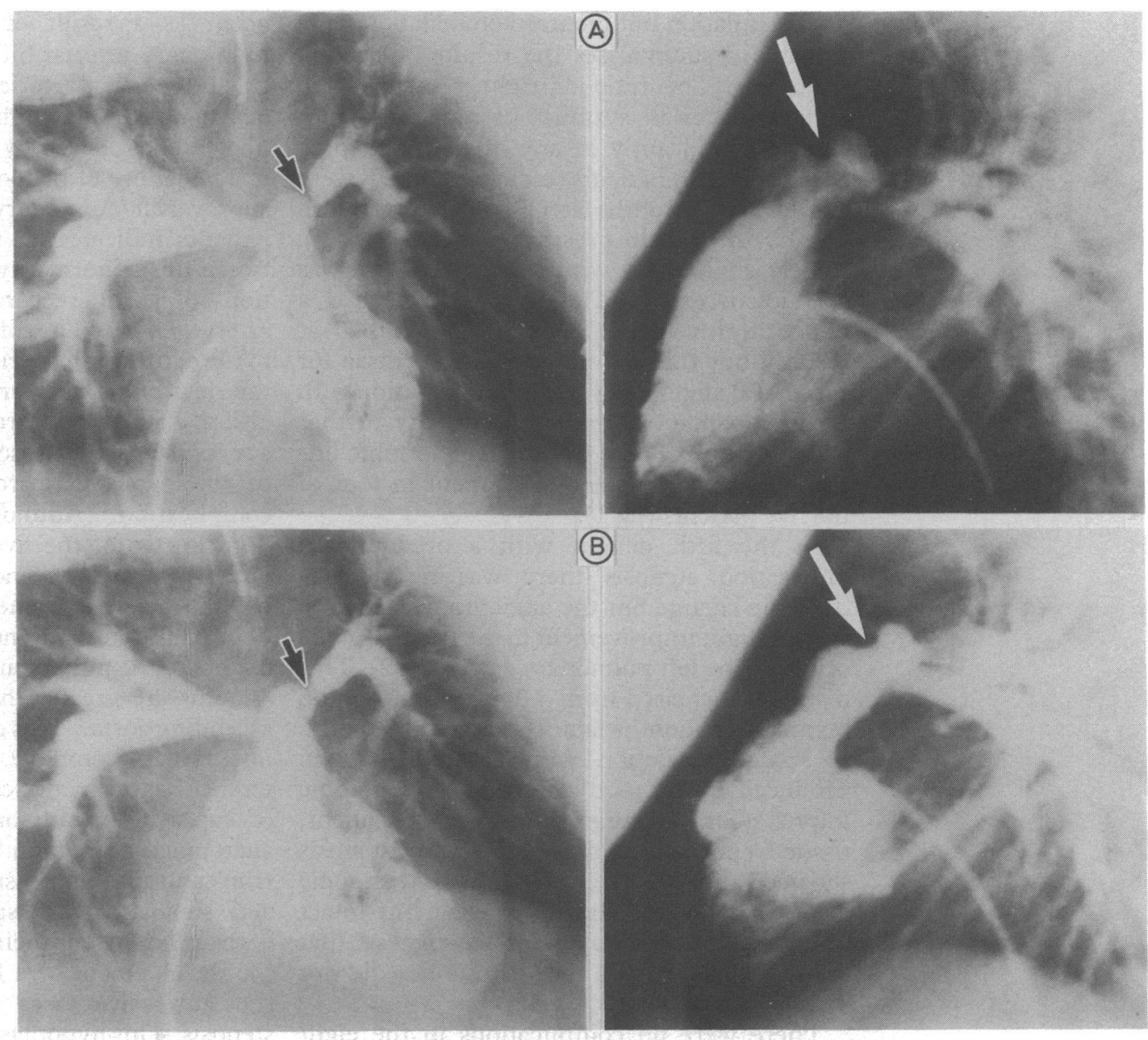

Scientific or Schneider Medintag) was guided across the stenotic segment. The balloon was inflated with one quarter strength contrast solution at the manufacturer's recommended pressure (usually 4-6 atmospheres) by a SciMed inflation device. It was inflated for 15 to 30 seconds under electrocardiographic and femoral arterial pressure monitoring and four dilatations were performed at each stenotic site. Only one patient required dilatation at two sites of narrowing (table 1 ).

After balloon dilatation repeat right ventricular and femoral arterial systolic pressures were recorded simultaneously. A right ventriculogram was obtained under the same conditions as the predilatation angiogram. The angioplasty was regarded as successful if (a) there was a fall in right ventricular systolic pressure to $<50 \%$ of femoral arterial systolic pressure or (b) there was an improvement of $>50 \%$ in the measured diameter of the narrowest segment on angiography or both. The angioplasty was also considered successful if these criteria were fulfilled on a follow up cardiac catheterisation, which was undertaken in three patients.

\section{Results}

All patients had moderate to severe supravalvar pulmonary stenosis on cardiac catheterisation. The right ventricular systolic pressure before dilatation ranged from 50 to $95 \mathrm{~mm} \mathrm{Hg}$ and this was $70-125 \%$ of the simultaneous femoral arterial systolic pressure. The pulmonary arterial pressure beyond the stenotic segment was normal in all patients. The subsequent gradient across the right ventricular outflow tract obstruction varied from 38 to $80 \mathrm{~mm} \mathrm{Hg}$ and was not reduced by dilatation (table 2 ).

In four patients the anastomotic segment was the pulmonary valve and in two it restricted the pulmonary valvar leaflets. This stenotic segment was not discrete and the distal main pulmonary artery also showed varying degrees of tubular hypoplasia. Therefore the diameter of the normal portion of the pulmonary artery distal to the site of obstruction could not be determined. In the fifth patient there was a slight stenosis in the main pulmonary artery but the origins of both the right and left pulmonary arteries were severely narrowed. Distal to the mild narrowing in the main pulmonary artery the pulmonary artery was $11.5 \mathrm{~mm}$ in diameter. The diameters of the left pulmonary artery and right pulmonary artery distal to severe bifurcation stenosis were 8 and $8.2 \mathrm{~mm}$ respectively.

Although the ratio of the selécted balloon diameter to the diameter of the narrowest segment measured on cinevideo images at cardiac catheterisation was $2 \cdot 0-3 \cdot 0$, remeasurement of the processed cineangiogram showed a ratio of 1.6-3.3 (median 2.0) (table 1 ). Three patients with ratios of $1 \cdot 6,1 \cdot 7$, and $2 \cdot 0$ at initial angioplasty underwent repeat dilatation at a later date with a balloon with a larger diameter. There was a long segment indentation in the balloon outline on inflation. This disappeared stenosed in the main pulmonary artery close to 
on full inflation but recurred on deflation.

Table 2 summarises the results of balloon dilatation. The ratio of right ventricular to femoral arterial systolic pressure did not change significantly in any of the eight procedures. Three patients (cases 1,2 , and 5) were restudied 2-3 months later. In two there was no improvement in the pressure (patients 1 and 5). Repeat angioplasty with a larger balloon was also unsuccessful. The third patient had a minor improvement in the ratio $(1.25$ to 0.90$)$ at restudy but this did not meet the criteria for successful angioplasty. A repeat dilatation with a larger balloon did not produce any further improvement. There was no angiographic improvement in the stenotic segment in four of the five patients (fig 1).

In the fifth patient with a predominant bifurcation stenosis there was no haemodynamic change but the angiogram seemed to show a slight improvement in the stenosis at the origin of the left pulmonary artery (fig 2 ). This diameter incteased from 3.0 to $3.5 \mathrm{~mm}$ but on restudy two months later it méasured $3.0 \mathrm{~mm}$. A second dilatation with a larger balloon produced no haemodynamic or angiographic improvement. At surgical repair in this patient, tissue from the wall of the bifurcation stenosis showed extensive adventitial fibrosis with some disorganisation of elastic lamellae but intact intimal and serosal layers. This suggests that the balloon stretched the stenosis but did not disrupt it.

There were no complications in the eight procedures. Transient hypotension, bradycardia, and electrographic ST segment changes were often seen during balloon inflation.

Surgical relief of the supravalvar stenosis with patch insertion into the stenotic regions was. later successful in patients 1 and 5. The other three patients continue to show appreciable obstruction of the ventricular outflow tract (echocardiographic Doppler gradients 40-60 mm Hg).

\section{Discussion}

Development of supravalvar pulmonary stenosis is the most common important complication after anatomical correction for complete transposition. ${ }^{2-4}$ Published reports describe successful surgical relief of the supravalvar obstruction in most patients. Balloon angioplasty for this lesion has been reported in five patients with success in only one patient ${ }^{5}$; also three patients later required operation.

Balloon angioplasty has been successfully used to dilatate vascular obstructions. Intimal and medial disruption was shown on histological examination in successful experimental dilatation of aortic coarctation in lambs. ${ }^{6}$ Good results from balloon dilatation were reported in human postoperative aortic coarctation and pulmonary artery stenosis. ${ }^{78}$ We performed balloon angioplasty in five patients with appreciable supravalvar pulmonary stenosis after anatomical correction for complete transposition. One patient (case 5) had major stenosis at the pulmonary arterial bifurcation and differed from the others. The bifurcation stenosis may occur as a result of the distortion of the pulmonary arterial bifurcation when the central pulmonary arteries are mobilised for reanastomosis at anatomical correction. It is less likely to be relieved by balloon angioplasty. ${ }^{4}$

The failure of balloon angioplasty to relieve supravalvar pulmonary stenosis in any of our patients indicates an intrinsic difference between this abnormality and the other obstructions of aortic recoarctation and pulmonary artery stenosis. The difference could be related to the nature of the pericardial patch inserted in the new pulmonary artery after coronary excision. Tanned pericardium retracts producing supravalvar stenosis; some thought that the use of autologous pericardium would avoid this complication. ${ }^{3}$ Autologous pericardium was used in two of the five patients in our series with supravalvar stenosis. Balloon dilatation was unsuccessful in these patients too.

In children with normal vessels the diameters of the pulmonary trunk and pulmonary annulus are greater than the diameter of the ascending aorta. ${ }^{9}$ This discrepancy is greater in infants with complete transposition. The difference has been implicated in the development of supravalvar pulmonary stenosis after the anatomical correction. ${ }^{10}$ The new pulmonary trunk and annulus are smaller and when there is also stenosis at the site of anastomosis and coronary excision, their size may contribute to the development of a hypoplastic segment in the supravalvar area rather than a discrete stenosis. This hypoplastic segment is less likely to be amenable to balloon angioplasty than a discrete stenosis.

In most patients with supravalvar stenosis after anatomical correction the stenotic segment lies close to the pulmonary valve. The diameter of the pulmonary annulus is therefore an important factor in the selection of the balloon because an oversized balloon may damage the pulmonary valve. Because the balloon lies across the pulmonary valve during dilatation it is difficult to keep it inflated for long periods without causing considerable haemodynamic deterioration, whereas in the peripheral pulmonary artery stenosis a balloon can be inflated for minutes.

Balloon angioplasty was not successful in any of the eight dilatation procedures attempted on five patients with supravalvar pulmonary stenosis developing after anatomical correction for complete transposition. These results were obtained despite the use of what we believed to be balloons of appropriate sizes (that is, compared with the size of the pulmonary valve annulus and the narrowest segment). Oversized balloons increase risk and there is little evidence that they are any more successful, particularly when this condition may be caused by multiple grades of stenosis within the same segment of vessel.

1 Perry SB, Keane JF, Lock JE. Interventional catheterisation in paediatric congenital and acquired heart disease. $\mathrm{Am}$ Cardiol 1988;61(suppl):109-17. 2 Quaegebeur JM, Rohmer J, Ottenkamp J, et al. The arterial 
switch operation-an eight year experience. $J$ Thorac Cardiovasc Surg 1986;92:361-84

3 Sidi D, Planche C, Kachaner J, et al. Anatomic correction of simple transposition of the great arteries in $\mathbf{5 0}$ neonates. Circulation 1987;75:429-35.

4 Wernovsky G, Hougen TJ, Walsh EP, et al. Midterm results after the arterial switch operation for transposition of the great arteries with intact ventricular septum: clinical, haemodynamic, echocardiographic and electro-
physiologic data. Circulation 1988;77:1333-44.

5 Zeevi B, Keane JF, Perry SB, Lock JE. Balloon dilatation of postoperative right ventricular outflow obstructions. J Am Coll Cardiol 1989;14:401-8.

6 Lock JE, Niemi T, Burke BA, Einzig S, Castaneda-Zuniga WR. Transcutaneous angioplasty of experimental aortic coarctation. Circulation 1982;66:1280-6.

7 Saul JP, Keane JF, Fellows KE, Lock JE. Balloon dilatation angioplasty of postoperative aortic obstructions. $\mathrm{Am}$ angioplasty of postope

8 Lock JE, Castaneda-Zuniga WR, Fuhrman BP, Bass JL. Balloon dilatation angioplasty of hypoplastic and stenotic pulmonary arteries. Circulation 1983;67:962-7.

9 de la Cruz MV, Anselmi G, Romero A, Monroy G. A qualitative and quantitative study of the ventricles and great vessels of normal children. Am Heart $J$ 1960;60: 675-90.

10 Bical O, Hazan E, LeCompte Y, et al. Anatomic correction of transposition of the great arteries associated with ventricular septal defect: midterm results in 50 patients. Circulation 1984;70:891-7. 